\title{
PENGEMBANGAN SEKOLAH SIAGA BENCANA DITINJAU DARI KEMAMPUAN ORIENTASI DAN MOBILITASI PADA JALUR EVAKUASI BENCANA STUDI KASUS MTSLB/A YAKETUNIS YOGYAKARTA
}

\author{
Danang Febriyantoko \\ Program Studi Desain Interior Institut Seni Indonesia Yogyakarta
}

\begin{abstract}
ABSTRAK
Sekolah memiliki peranan penting dalam upaya membangun kesiapsiagaan menghadapi bencana, sebagai satuan pendidikan YAKETUNIS memiliki tanggung jawab menyelanggarakan pendidikan agar siswa mampu mengembangkan potensi diri dan membangun budaya termasuk budaya kesiapsiagaan menghadapi bencana.Pelatihan orientasi dan mobilitasi bagi penyandang disabilitas penting dilakukan sebagai salah satu upaya pengenalan lingkungan dalam program sekolah siaga bencana. Kemampuan mengenali lingkungan sekolah dapat lebih dioptimalkan dengan penggunaan peta jalur evakuasi bencana yang telah diberi huruf braile, sehingga pada saat mata pelajaran orientasi dan mobilitasi peta tersebut dapat digunakan sebagai rujukan untuk lebih mengenali lingkungan fisiknya serta membekali diri dalam kesiapsiagaan menghadapi bencana.
\end{abstract}

\section{PENDAHULUAN}

Rentetan bencana alam besar sering menimpa Indonesia dalam interval waktu yang relatif pendek, di Yogyakarta merupakan daerah yang rawan terhadap ancaman bencana alam termasuk bencana gempa bumi. Terakhir kali Yogyakarta terjadi gemba bumi tektonik dengan skala 5,9 SR pada tahun 2006 yang menyebabkan ribuan korban jiwa, kerugian harta benda serta lumpuhnya lini-lini kehidupan. Anak-anak merupakan kelompok rentan yang sering kali menjadi korban ketika benca terjadi, terutama anak-anak disabilitas termasuk penyandang tunanetra.

YAKETUNIS (Yayasan Kesejahteraan Tunanetra Islam) merupakan lembaga pendidikan formal yang khusus diperuntukan bagi anak dan remaja penyandang disabilitas dalam hal keterbatasan penglihatan. Terdapat 28 orang siswa yang dibina di yayasan ini dengan latarbelakang yang berbeda-beda. Kegiatan yang berlangsung di YAKETUNIS ialah kegitaan belajar mengajar yang berlangsung dari hari senin hingga sabtu. Selain kegiatan belajar mengajar di YAKETUNIS juga terdapat fasilitas asrama yang disediakan untuk siswa.

Sekolah memiliki peranan penting dalam upaya membangun kesiapsiagaan menghadapi bencana, di dalam kesiapsiagaan menghadapi bencana tentunya membutuhkan pengetahuan yang baik mengenai resiko bencana yang dapat terjadi. Sebagai satuan pendidikan YAKETUNIS memiliki tanggung jawab menyelanggarakan pendidikan agar siswa mampu mengembangkan potensi diri dan membangun budaya termasuk budaya kesiapsiagaan menghadapi bencana. Dalam prakteknya beberapa materi pelajaran terkait kebancanaan dapat diberikan disela-sela materi pembelajaran, namun hal tersebut masih perlu dikembangkan demi terwujudnya sekolah siaga bencana di lingkungan YAKETUNIS.

Sosialisai akan pentingnya sekolah siaga bencana beberapa kali pernah dilakukan di YAKETUNIS diantaranya dilakukan oleh Perkumpulan Lingkar terhadap guru-guru di lingkungan sekolah pada tahun 2015, hasil dari sosialisasi tersebut diharapkan guru-guru dapat membina, membimbing serta mengarahkan siswa apabila bencana terjadi. Sosialisai 
tersebut masih perlu terus dikembangkan demi terwujudnya sekolah siaga bencana. Kajian ini akan membahas kemampuan siswa dalam mengenal lingkungan fisik sekolahnya melalui kegiatan orientasi dan mobilitasi yang akan berguna bagi pengembangan sekolah siaga bencana.

\section{PERMASALAHAN}

Anak tunanetra mengalami keterbatasan dalam hal penerimaan informasi, pada anak dengan kondisi normal informasi dapat diperoleh melalui indera pengelihatan, sedangkan pada anak penyandang tunanetra informasi tersebut dapat diterima melalui indera lain seperti indera penciuman, peraba dan perasa. Masih terbatasnya media informasi kebencanaan menyebabkan anak dengan tunanetra kesulitan mengakses atau mendapatkan informasi sehingga mengurangi kesiapsiagaan siswa dalam menghadapi bencana.

Pelatihan orientasi dan mobilitasi kerap dilakukan oleh sekolah untuk melatih siswa agar mandiri beraktifitas pada lingkungan fisiknya, pengenalan lingkungan ini menjadi penting termasuk pengenalan lingkungan yang aman untuk berlindung ketika terjadi bencana seperti gempa bumi siswa dapat mengerti dan paham apa yang harus dilakukan ketika terjadi bencana.

\section{ORIENTASI \& MOBILITASI (OM)}

Orientasi merupakan peroses penggunaan seluruh komponen indera yang masih ada untuk mementukan posisi seseorang terhadap benda-benda penting yang ada disekitarnya. Sedangkan mobilitas adalah kemampuan untuk bergerak dari satu posisi tetap menuju posisi yang diinginkan dibagian lain dari lingkungan yang sama. Berdasarkan pengertian tersebut, dapat disimpulkan bahwa Orientasi dan Mobilitas (OM) adalah kemampuan bergerak dari satu tempat ke tempat yang lain dengan menggunakan semua indera yang masih ada untuk menentukan posisi seseorang terhadap benda-benda penting yang ada di sekitarnya, baik secara temporal ataupun spasial.

Prinsip-prinsip orientasi dan mobilitas adalah bahwa pada akhirnya penyandang tunanetra terlatih untuk bertanya pada dirinya sendiri sebelum bergerak untuk berjalan dan melawat, dengan pertanyaan tentang: Where am i (dimana saya berada?), Where is my objective (kemana tujuan saya?), dan How do i get there (bagaimana saya samapai kesana?). Dari jawaban atas pertanyaan tersebut tunanetra dapat membuat suatu rencana perjalanan, penyandang tunanetra perlu mengetahui ciri-ciri medan dan beberapa petunjuk yang dapat membantunya. Pembelajaran OM dimulai dari apa yang diketahui penyandang tunanetra menuju apa yang belum diketahuinya, dari yang konkrit ke yang abstrak, dari yang mudah ke yang sukar, dari yang sederhana ke yang kompleks, dari lingkungan yang sepi ke lingkungan yang ramai, dan dari lingkungan terdekat menuju ke lingkungan yang lebih luas.

\section{MENAJEMEN SEKOLAH SIAGA BENCANA}

Sekolah siaga bencana merupakan upaya membangun kesiapsiagaan sekolah terhadap bencana dalam rangka menggugah kesadaran seluruh unsur-unsur pendidikan baik individu maupun kolektif di sekolah dan lingkungan sekolah baik sebelum, sesaat maupun setelah terjadinya bencana. Tujuan dari terbentuknya sekolah siaga bencana adalah membangun budaya siaga dan budaya aman di sekolah dengan bersama-sama pemangku kebijakan penanganan bencana. Meningkatkan kapasitas institusi sekolah serta individu 
untuk mewujudkan tempat belajar yang lebih aman bagi siswa, guru dan anggota komunitas sekolah.

Menurut Undang-Undang Nomor 24 Tahun 2007 Pasal 1 tentang Penanggulangan Bencana, Kesiapsiagaan adalah "serangkaian kegiatan yang dilakukan untuk mengantisipasi bencana melalui pengorganisasian serta melalui langkah yang tepat guna dan berdaya guna". Hal ini mencakup pengembangan / peningkatan keseluruhan strategi kesiapan, kebijakan, struktur institusional, peringatan dan kemampuan meramalkan, serta rencana yang menentukan langkah-langkah yang dicocokkan untuk membantu komunitas yang berisiko menyelamatkan hidup dan aset mereka dengan cara waspada terhadap bencana dan melakukan tindakan yang tepat dalam mengatasi ancaman yang akan terjadi atau bencana sebenarnya.

Kemampuan tersebut juga dapat dinalar melalui adanya simulasi regular dengan kerja sama berbagai pihak terkait yang dilembagakan dalam kebijakan lembaga pendidikan tersebut untuk mentransformasikan pengetahuan dan praktik penanggulangan bencana dan pengurangan risiko bencana kepada seluruh warga sekolah sebagai konstituen lembaga pendidikan

\section{METODE}

Dengan cara mengikuti proses pembelajaran Orientasi dan Mobilitas yang telah diajarkan oleh pihak sekolah kemudian mengkombinasikanya dengan pengetahuan mengenai manajemen kebancanaan dengan cara menaganalisa spot-spot yang ada di sekolah untuk lebih mengenali lingkungan fisik. Penelitian terdahulu menunjukan bahwa pencantuman kebutuhan khusus penyandang disabilitas dalam semua tahap manajemen bencana khususnya pada tahap perencanaan dan kesiapsiagaan secara significant dapat mengurangi kerentanan serta meningkatkan efektifitas dalam usaha tanggap darurat dan recovery pasca bencana yang dilakukan pemerintah (United Nation, 2012). Penyandang disabilitas dalam perencanaan menanggulangi bencana menjadi penting karena lebih mengetahui kebutuhan mereka sendiri, kekhususan dan kompleksitas yang dimiliki oleh penyadang disabilitas membuat penanganan dan kebutuhan yang lebih spesifik.

Tabel 1. Petunjuk untuk penanganan kebutuhan khusus

\begin{tabular}{|l|l|l|}
\hline Jenis Disabilitas & Kebutuhan & Sistem Peringatan Bencana \\
\hline $\begin{array}{l}\text { Kecacatan / } \\
\text { Gangguan Visual }\end{array}$ & $\begin{array}{l}\text { - Landmark / Petunjuk } \\
\text { - Handrails } \\
\text { - Dukungan Personal } \\
\text { - Pencahayaan yang Baik } \\
\text { - Antrian Terpisah }\end{array}$ & $\begin{array}{l}\text { - Sistem sinyal berbasis suara/alarm } \\
\text { - Pengumuman Lisan } \\
\text { - Poster yang ditulis dengan huruf yang besar } \\
\text { dan warna yang mencolok. }\end{array}$ \\
\hline $\begin{array}{l}\text { Kecacatan / } \\
\text { Gangguan Pendengaran }\end{array}$ & $\begin{array}{l}\text { - Bantuan Penglihatan } \\
\text { - Komunikasi dengan Gambar } \\
\text { - Antrian Terpisah }\end{array}$ & $\begin{array}{l}\text { - Sistem sinyal berbasis visual (simbol, dll) } \\
\text { - Sinyal kedip lampu }\end{array}$ \\
\hline Gecacatan / & $\begin{array}{l}\text { - Berbicara Pelan } \\
\text { - Bahasa yang Sederhana } \\
\text { - Dukungan Personal } \\
\text { - Antrian Terpisah }\end{array}$ & $\begin{array}{l}\text { - Sinyal khusus (bendera merah, dll) } \\
\text { - Pengumuman yang lengkap dan jelas oleh } \\
\text { tenaga siaga bencana }\end{array}$ \\
\hline Gangguan Fisik & $\begin{array}{l}\text { - Baju hangat / selimut } \\
\text { - Kasur, tempat kering, alat higienis } \\
\text { - Dukungan Personal } \\
\text { - Alat Bantu } \\
\text { - Sarana Publik yang dimodifikasi } \\
\text { (pegangan tangan, jalan landai, dll) } \\
\text { - Antrian Terpisah }\end{array}$ & \\
\hline
\end{tabular}


Siswa MTsLB/A Yaketunis umumnya memiliki keterbatasan dalam penglihatan / visual dengan tingkatan yang berbeda-beda, kemudian dipilih sample siswa kelas VIII yang telah menerima pelajaran orientasi dan mobilasi sebagai responden penelitian. Siswa tersbut kemudian mengobservasi lingkungan sekolah yang memiliki kerentanan terhadap bencana, kegiatan orientasi dan mobilitasi kemudian dikembangkan keluar lingkungan sekolah dengan titik kumpul evakuasi menjadi titik akhir kegiatan orientasi mobilitasi.

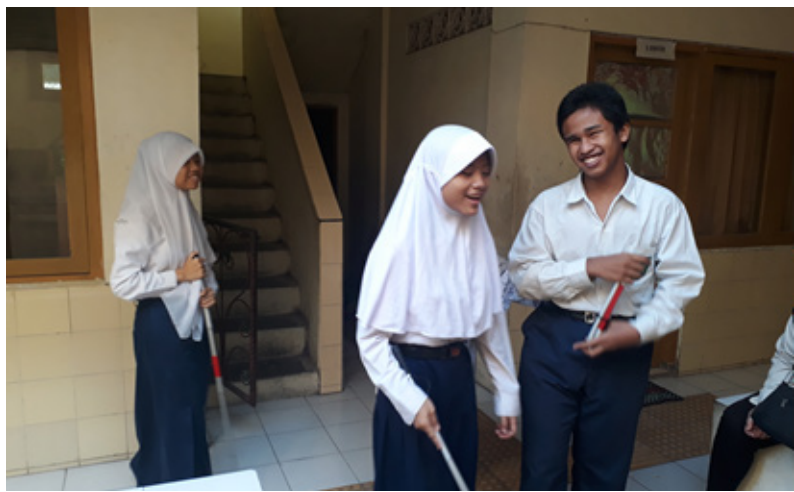

Gambar 1. Siswa mulai melakukan orientasi dan mobilitas terhadap lingkungan sekolah Sumber : Dokumen pribadi

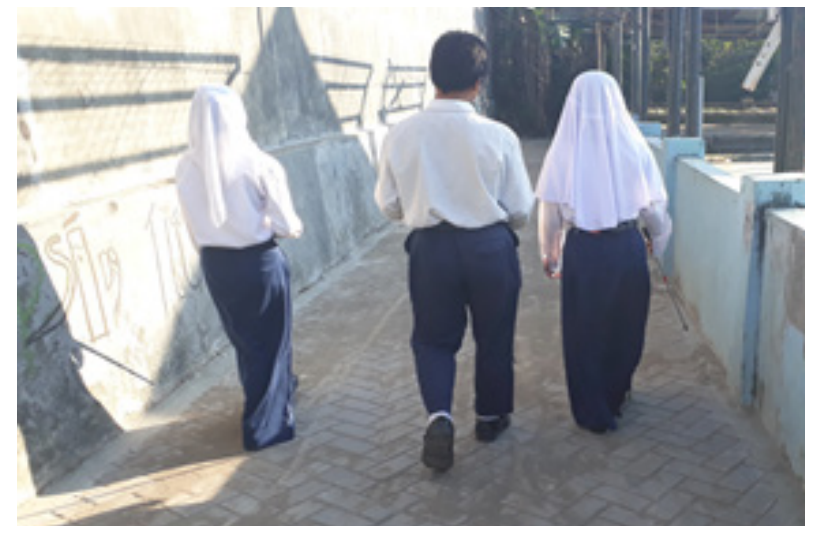

Gambar 2. Materi orientasi dan mobilitas juga dikembangkan keluar lingkungan sekolah untuk menelusuri titik kumpul evakuasi. Sumber : Dokumen pribadi

Setelah melakukan penulusuran lingkungan sekolah tahap selanjutnya adalah membuat peta / denah rencana evakuasi yang dapat dibaca dan dipahami oleh siswa tunanetra. Pumbuatan peta evakuasi tersebut diawali dengan memberi teori pengetahuan mengenai sekolah siaga bencana, apa itu bencana, bagaimana potensinya, apa bahanya, tanda-tandanya serta apa yang harus dilakukan untuk mengahadapinya.

Pembuatan peta jalur evakuasi bencana dibantu oleh guru mata pelajaran orientasi dan mobilitasi, dengan menambahkan huruf braile terhadap rencana peta yang telah dibuat. Diharapkan dengan penambahan huruf braile tersebut dapat membatu siswa tunanetra untuk membaca peta. Penamaan tiap-tiap ruang kelas akan menggunakan huruf braile, sebagai penanda tiap ruang dalam peta siswa dituntut untuk lebih mengenali lingkunganya terkait dengan kedekatan antar ruang dan aksesibilitas untuk menuju ruang yang dituju maupun titik kumpul yang telah ditentukan.

Peta jalur evakuasi sekolah adalah peta yang ditujukan untuk membuat seseorang dapat menyikapi saat terjadi bencana dan tidak berhamburan saat terjadi bencana, panik pada saat terjadi bencana melainkan dapat memposisikan diri apa yang akan mereka lakukan 
dengan melihat petunjuk yang ada demi menekan jumlah korban yang disebabkan oleh kepanikan saat terjadi bencana seperti gunung meletus, banjir dan gempa bumi. Penentuan titik jalur evakuasi serta tempat berkumpul (assemble point) merupakan perencanaan peta evakuasi dengan cara menentukan lintasan terpendek dan efektif menuju titik kumpul yang telah disepakati. Penentuan lintasan terpendek memperhatikan alternatif jalur-jalur yang dapat dilalui menuju titik berkumpul.

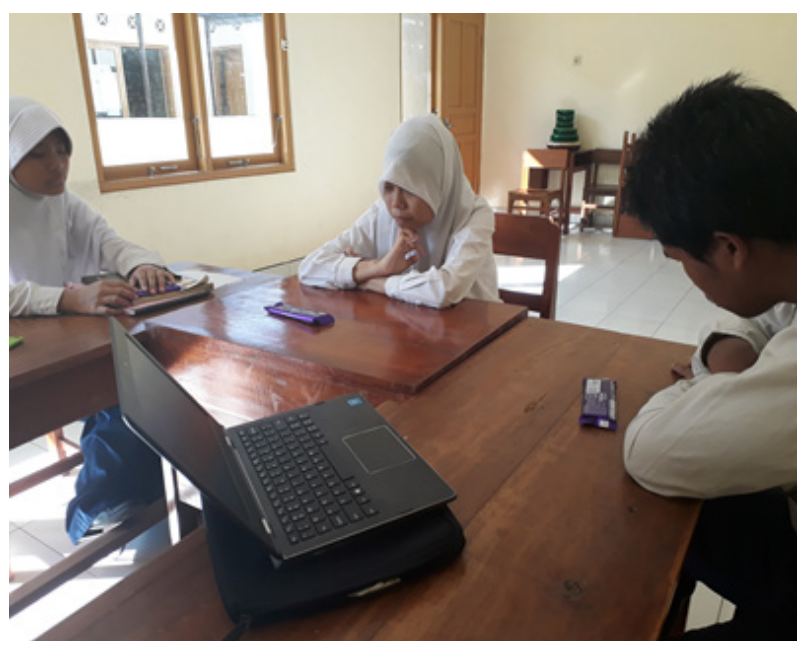

Gambar 3. Memberi materi teori berupa audio tentang sekolah siaga bencana Sumber : Dokumen pribadi.

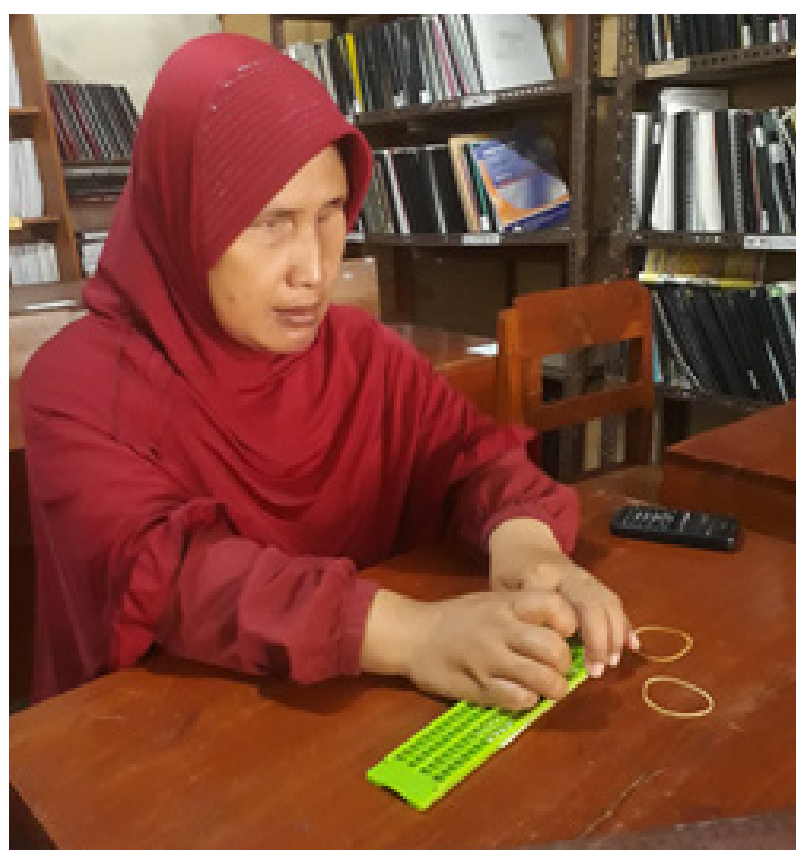

Gambar 4. Membuat huruf braile pada peta dibantu oleh guru mata pelajaran orientasi dan mobitas Sumber : Dokumen pribadi 
DENAH JALUR EVAKUASI GEMPA BUMI MTS YAKETUNIS

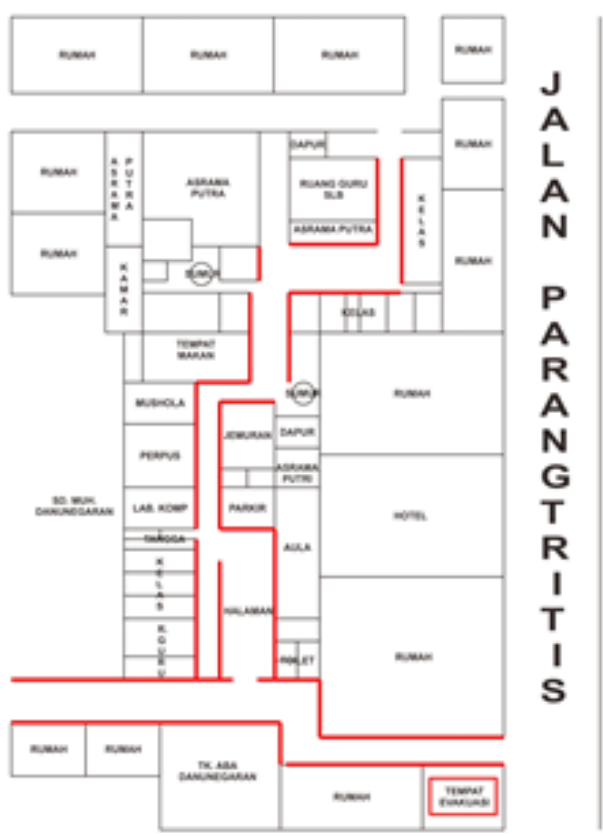

Gambar 5. Rencana Peta / Denah jalur evakuasi bencana gempa bumi Sumber : Dokumen pribadi

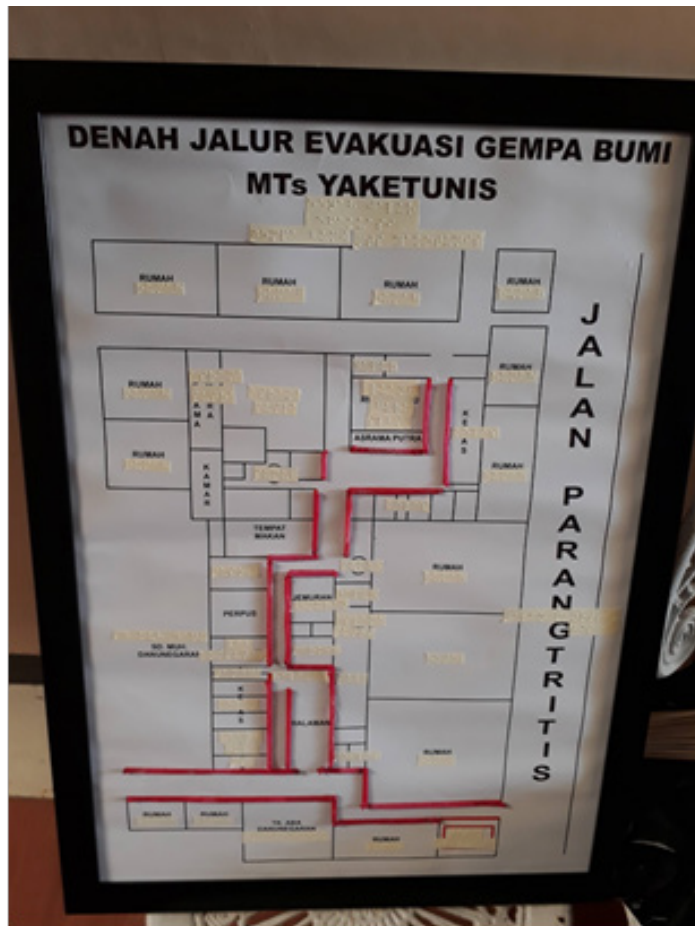

Gambar 6. Denah jalur evakuasi yang telah ditambahkan huruf braile Sumber : Dokumen pribadi 


\section{KESIMPULAN DAN SARAN}

Secara umum siswa telah mampu mengidentifikasi lingkungan fisik sekolahnya, pengetahuan mengenai kebencanaan telah diketahui oleh siswa termasuk kesiapsiagaan mengahadapi bencana, apa yang harus dilakukan pada saat bencana terjadi, dan dimana tempat yang harus dituju sebagai titik kumpul. Kemampuan mengenali lingkungan sekolah dapat lebih dioptimalkan dengan penggunaan peta jalur evakuasi bencana yang telah diberi huruf braile, sehingga pada saat mata pelajaran orientasi dan mobilitasi peta tersebut dapat digunakan sebagai rujukan untuk lebih mngenali lingkungan fisiknya serta membekali diri dalam kesiapsiagaan menghadapi bencana

Pendidikan kebancanaan termasuk didalamnya manajemen kebencaaan harus terus menerus dievaluasi dan dilatih oleh seluruh komponen sekolah, dibutuhkan kesadaran baik guru maupun siswa untuk terus membekali diri menghadapi bencana yang sewaktu-waktu dapat terjadi.

\section{DAFTAR PUSTAKA}

Handicap International. (2005). How To Include Disability Issues in Disaster Management, Dhaka: Handicap International Bangladesh.

Probosiwi, Ratih (2013). Keterlibatan Penyandang Disabilitas dalam Penanggulangan Bencana, Jurnal Penanggulangan Bencana Vol. 4, No. 2 Tahun 2013 Hal. 13-22.

United Nations. (2012). Disability, Natural Disasters and Emergency Situations. Dipetik : November 19, 2012, dari UN Enable: www.un.org/disabilities/default.asp?id=1546.

Undang-Undang Nomor 24 Tahun 2007 Pasal 1 tentang Penanggulangan Bencana 